\title{
Aplicação do plasma rico em plaquetas (PRP) em ferida acometida de deiscência após laparotomia exploratória em equino: relato de caso
}

Mariana Lopes da Conceiçao, Gustavo dos Santos Rosa, Marilia Ferrari Marsiglia, Ana Liz Garcia Alves, Carlos Alberto Hussni, Celso Antônio Rodrigues, Betsabéia Heloísa Gentilha Milani, Marcos Jun Watanabe

*Autor correspondente

e-mail: mari.lopesc@hotmail.com

\section{Resumo}

O plasma rico em plaquetas (PRP) consiste em uma alta concentração de plaquetas em um pequeno volume de plasma, sendo em média quatro vezes maior do que a concentração sérica. Quando ativadas, as plaquetas liberam fatores de crescimento e proteínas que residem no seu interior em grânulos (grânulos densos, lisossomos e alpha grânulos). Há dezenas de fatores de crescimento, entre os quais destacam-se o TGF $\beta$ (transforming growth factor) e PDGF-BB (platelet-derived growth factor), VEGF (vascular endothelial growth factor) e EGF (epidermal growth factor). Tais fatores ligam-se aos seus receptores transmembrânicos na superfície de células locais ou circulantes, iniciando, assim, a expressão de proteínas responsáveis por quimiotaxia, angiogênese, síntese de matriz extracelular, diferenciação celular e proliferação, que ampliam o poder de reparação tecidual. Dessa forma, a liberação de fatores de crescimento em uma região lesada promove o aumento da permeabilidade vascular, permitindo que células atraídas quimicamente pela inflamação (principalmente leucócitos) e pelos fatores degranulados pelos alpha grânulos (quimiotaxia) possam realizar transposição através do endotélio rumo ao foco acometido. Além de glóbulos brancos, diversas outras células, como células-tronco mesenquimais adultas, osteoblastos, fibroblastos, células endoteliais e epidermais, expressam receptores de membrana para os fatores de crescimento degranulados pelas plaquetas. A habilidade de reparar feridas cutâneas após injúria é essencial para a sobrevivência. Em equinos, feridas acima de carpo e tarso tendem a cicatrizar rapidamente e sem complicações. Foi atendido no Hospital Veterinário da UNESP, campus de Botucatu, um equino de 10 meses de idade, fêmea, da raça Quarto de Milha apresentando desconforto abdominal agudo. 0 animal foi encaminhado para laparotomia exploratória, no qual foi diagnosticado compactação de cólon maior e menor. Após o procedimento cirúrgico, o animal passou a apresentar peritonite, sendo realizada antibioticoterapia. Por apresentar dor devido à peritonite, o animal passou a ficar em decúbito esternal por longos períodos de tempo, havendo 
contaminação da ferida cirúrgica com deiscência. Dessa forma, realizou-se a duas aplicações de PRP nos bordos da ferida, havendo um resultado satisfatório, uma vez que houve proliferação de tecido de granulação e maior coaptação dos bordos. O protocolo para obtenção do PRP consistiu em duas centrifugações (300g por 5 minutos e $700 \mathrm{~g}$ por 17 minutos) e dois repousos (30 e 40 minutos). Concluiu-se que o plasma rico em plaquetas foi efetivo em acelerar o processo de reparação, além de ter auxiliado no combate à infecção, uma vez que o tecido de granulação tem como característica ser resistente à infecção.

Palavras-chave: Plasma rico em plaquetas. Equinos. Reparação tecidual. 